DOI: $10.17516 / 1998-2836-0174$

УДК $662.74 ; 662.613$

\title{
Crush and Acid Resistance \\ of Microsphere Narrow Fractions from Fly Ash \\ as the Basis of Composite Materials
}

\author{
Galina V. Akimochkina, \\ Elena S. Rogovenko and Elena V. Fomenko* \\ Institute of Chemistry and Chemical Technology SB RAS \\ FRC "Krasnoyarsk Science Center SB RAS" \\ Krasnoyarsk, Russian Federation
}

Received 20.12.2019, received in revised form 05.02.2020, accepted 10.04.2020

\begin{abstract}
The crush test and acid resistance of microsphere narrow fractions with average diameter $d_{\mathrm{av}}$ of 5,8 and $25 \mu \mathrm{m}$ of the $\mathrm{SiO}_{2}-\mathrm{Al}_{2} \mathrm{O}_{3}-\mathrm{FeO}$ system and with $d_{\text {av }}$ of 4 and $10 \mu \mathrm{m}$ the $\mathrm{CaO}-\mathrm{SiO}_{2}-\mathrm{Al}_{2} \mathrm{O}_{3}-$ $\mathrm{FeO}$ system separated from fly ash from pulverized combustion of Ekibastuz and Irsha-Borodinsky coals were studied. It has been established that all investigated ash fractions of both raw materials are characterized by high strength: microspheres of a larger narrow fraction with $d_{\mathrm{av}}=25 \mu \mathrm{m}$ are not destroyed by compressive loading at pressures up to $51.7 \mathrm{MPa}$, dispersed narrow fractions of microspheres with $d_{\mathrm{av}} \leq 10 \mu \mathrm{m}$ - up to $68.9 \mathrm{MPa}$. Microsphere narrow fractions with aluminosilicate composition have satisfactory acid resistance; the weight loss after treatment with $15 \%$ hydrochloric acid at $65^{\circ} \mathrm{C}$ for 30 minutes was $10-15$ wt. $\%$.
\end{abstract}

Keywords: microspheres, fly ash, narrow fraction, crush and acid resistance, proppants.

Citation: Akimochkina G.V., Rogovenko E.S., Fomenko EV. Crush and acid resistance of microsphere narrow fractions from fly ash as the basis of composite materials, J. Sib. Fed. Univ. Chem., 2020, 13(2), 189-200. DOI: 10.17516/1998-2836-0174

(c) Siberian Federal University. All rights reserved

This work is licensed under a Creative Commons Attribution-NonCommercial 4.0 International License (CC BY-NC 4.0).

* Corresponding author E-mail address: agv3107@mail.ru 


\title{
Определение сопротивления раздавливанию \\ и кислотостойкости узких фракций микросфер \\ летучих зол как основы композитных материалов
}

\author{
Г.В. Акимочкина, \\ Е.С. Роговенко, Е.В. Фоменко \\ Институт химии и химической технологии СО РАН \\ ФИЦ «Красноярский научный иентр СО РАН» \\ Российская Федерация, Красноярск
}

\begin{abstract}
Аннотация. Выполнено исследование сопротивления раздавливанию и кислотостойкости узких фракций микросфер со средним диаметром $d_{\mathrm{cp}} 5,8$ и 25 мкм системы $\mathrm{SiO}_{2}-\mathrm{Al}_{2} \mathrm{O}_{3}-\mathrm{FeO}$ и с $d_{\text {cp }} 4$ и 10 мкм системы $\mathrm{CaO}-\mathrm{SiO}_{2}-\mathrm{Al}_{2} \mathrm{O}_{3}-\mathrm{FeO}$, выделенных из летучих зол от пылевидного сжигания экибастузского и ирша-бородинского углей. Установлено, для всех исследуемых зольных фракций обоих сырьевых источников характерна высокая прочность: микросферы более крупной узкой фракции с $d_{\mathrm{cp}}=25$ мкм не подвергаются разрушению под воздействием сжимающей нагрузки при давлении до 51.7 МПа, дисперсные узкие фракции микросфер с $d_{\mathrm{cp}} \leq 10$ мкм - до 68.9 МПа. Узкие фракции микросфер алюмосиликатного состава обладают удовлетворительной кислотостойкостью, потеря массы после обработки $15 \%$ соляной кислотой при $65^{\circ} \mathrm{C}$ в течении 30 минут составила $10-15$ мас. \%.
\end{abstract}

Ключевые слова: микросферы, летучая зола, узкая фракция, прочность, кислотостойкость, пропанты.

Цитирование: Акимочкина, Г.В. Определение сопротивления раздавливанию и кислотостойкости узких фракций микросфер летучих зол как основы композитных материалов / Г.В. Акимочкина, Е.С. Роговенко, Е.В. Фоменко // Журн. Сиб. федер. ун-та. Химия, 2020. 13(2). С. 189-200. DOI: 10.17516/1998-2836-0174

\section{Введение}

Проблема загрязнения окружающей среды техногенными отходами чрезвычайно актуальна как в настоящее время, так и на ближайшую перспективу. При экологическом регулировании деятельности ТЭС особое внимание обращено на летучие золы, которые вносят основной вклад в суммарное количество отходов теплоэнергетики, составляя при пылевидном сжигании угля 60-95 \% [1,2]. В связи с этим необходимо исследование физико-химических свойств зольных микрочастиц, установление путей снижения их эмиссии, определение перспективных областей сырьевого применения.

Перспективным направлением использования летучих зол, требующим большого количества исходного сырья, является получение композитных керамических материалов различного назначения [3, 4]. В последние годы показана возможность получения кордиеритовой керамики, применяемой в качестве носителей катализаторов, огнеупорных материалов, теплообменников, для производства которой используется 64-68 мас. \% золы макрокомпонентного 
состава $\mathrm{SiO}_{2}-58, \mathrm{Al}_{2} \mathrm{O}_{3}-29$ мас. \% [5]. Получена керамическая строительная плитка, содержащая 50-90 мас. \% золы состава $\mathrm{SiO}_{2}-42, \mathrm{Al}_{2} \mathrm{O}_{3}-40, \mathrm{CaO}-6$ мас. \% [6]. Из золы в количестве 75-85 мас. \%, содержащей $\mathrm{SiO}_{2}-47, \mathrm{Al}_{2} \mathrm{O}_{3}-41$ мас. \%, синтезированы композитные керамические мембранные подложки для микрофильтрационных мембран [7].

Среди востребованных композитных материалов, производство которых носит крупнотоннажный характер, следует отметить высокопрочные облегченные гранулы пропантов, применяемые для крепления трещин при добыче нефти и газа методом гидравлического разрыва пласта [8]. К физико-химическим характеристикам пропантов, влияющим при их использовании на проводимость трещины, относятся: насыпная плотность, сопротивление раздавливанию, растворимость в кислотах, сферичность, округлость, массовое содержание $\mathrm{Al}_{2} \mathrm{O}_{3}$ и $\mathrm{Fe}_{2} \mathrm{O}_{3}$ [9]. Традиционно исходным материалом для производства пропантов служит алюмосиликатное сырье: боксит, содержащий $\mathrm{Al}_{2} \mathrm{O}_{3}-65-75$ мас. \% [10], каолиновая глина - $\mathrm{Al}_{2} \mathrm{O}_{3}-$ $40-43$ мас. \% [11] и обожженный каолин $-\mathrm{Al}_{2} \mathrm{O}_{3}-30-45$ мас. \% с добавлением 0.5-30 мас. \% упрочняющих добавок отдельно или в виде смеси (глиноземная пыль, бадделеит, обожженный при температуре $800-1100{ }^{\circ} \mathrm{C}$ циркониевый концентрат и необожженный боксит) [12]. Для получения облегченных пропантов в их состав вводят различные наполнители, в том числе полые стеклянные или керамические микросферы [8, 13]. Приняты попытки использовать в качестве облегчающего компонента концентраты ценосфер летучих зол [14]. Показано [15], что благодаря низкой насыпной плотности и возможности выделения частиц повышенной прочности узкие фракции ценосфер размером $-0.4+0.2$ мм с насыпной плотностью $0.34-0.64$ г/см ${ }^{3}$ перспективны для получения облегченных композитных материалов различного назначения, в том числе пропантов.

В качестве алюмосиликатного сырья для получения высокопрочных керамических пропантов низкой плотности могут применяться летучие золы [16]. Использование узких фракций микросферических компонентов летучих зол определенного размера, состава и строения с воспроизводимыми физико-химическими характеристиками [15, 17-19], удовлетворяющих техническим требованиям к пропантам [9], позволит получить материалы с улучшенным свойствами на основе крупнотоннажных отходов тепловой энергетики.

Целью работы являлось определение сопротивления раздавливанию и кислотостойкости узких фракций зольных микросфер для оценки перспективности их использования в качестве основы композитных материалов.

\section{Экспериментальная часть}

В качестве объектов исследования были использованы узкие фракции дисперсных микросфер, выделенные из зол-уноса от пылевидного сжигания разных типов углей: каменного экибастузского на Рефтинской ГРЭС (серия В) и бурого канско-ачинского (Ирша-Бородинское месторождение) на Красноярской ТЭЦ-2 (серия Кр). Согласно классификации летучих зол по стандарту ASTM C618 [20], зола-уноса от сжигания углей Экибастузского бассейна относится к классу F (алюмокремнистые), Канско-Ачинского бассейна - к классу С (высококальциевые).

Выделение узких фракций выполнено с использованием метода аэродинамического разделения, реализованного на центробежном лабораторном классификаторе 50 ATP (Hosokawa 
ALPINE, Германия). Подробно схема классификатора и принцип его действия изложены в работах $[17,18]$, режимы аэродинамического разделения и физико-химические характеристики полученных узких фракций приведены в работах $[17,19]$.

Насыпную плотность определяли на автоматизированном анализаторе Autotap (Quantachrome Instruments, CША). Распределение частиц по размеру определено на лазерном анализаторе MicroTec 22 (Fritsch, Германия). Величину среднего диаметра глобул определяли по трем независимым измерениям. Абсолютная погрешность измерений не превышала \pm 0.3 мкм.

Химический состав, включающий содержание оксидов кремния, алюминия, железа, кальция, магния, калия, натрия, титана и серы, а также потери при прокаливании (п.п.п.) определяли методами химического анализа согласно ГОСТ 5382-91 [21].

Количественный фазовый состав определяли методом порошкового рентгенофазового анализа с применением полнопрофильного подхода Ритвельда [22] с минимизацией производной разности по методике, применяемой ранее для алюмосиликатных микросфер зол-уноса [23]. Дифракционные данные были получены на порошковом дифрактометре X'Pert Pro MPD (PANalytical, Hидерланды) с твердотельным детектором PIXcel и вторичным графитовым монохроматором для $\mathrm{Cu}_{\mathrm{K \alpha}}$-излучения.

Исследование морфологии глобул выполняли на порошковых образцах с применением сканирующего электронного микроскопа ТМ-1000 (Hitachi, Япония).

Определение прочностных характеристик узких фракций микросфер под воздействием сжимающей нагрузки и их растворимости в кислотах осуществляли по стандартным методикам испытаний согласно ГОСТ Р 51761-2013 «Пропанты алюмосиликатные. Технические условия» [9].

\section{Результаты и обсуждение}

Насыпная плотность, химический и фазовый составы узких фракций микросфер летучих зол от сжигания разных типов энергетических углей, выбранных для исследования в качестве основы композитных материалов, приведены в табл. 1.

Одним из ключевых параметров композитных материалов, влияющих на их свойства, является насыпная плотность. В частности, использование облегченных пропантов позволяет применять менее концентрированные жидкости гидроразрыва, обеспечивает равномерное распределение гранул и длительность их присутствия во взвешенном состоянии. Согласно техническим требованиям [9] значения насыпной плотности гранул пропантов

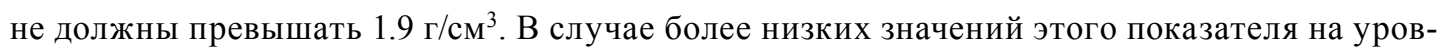

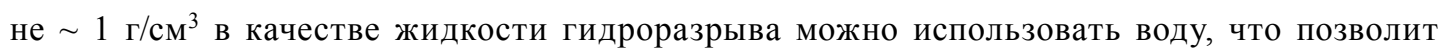
существенно снизить затраты, способствуя росту экономической эффективности процесса [8]. Выбранные узкие фракции зольных микросфер характеризуются низкими значениями

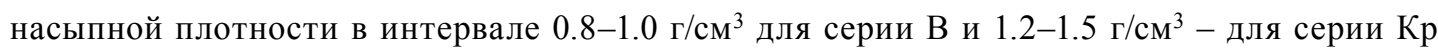
(табл. 1), что определяет перспективность их использования в качестве основы облегченных материалов.

Фракции микросфер обладают узким распределением частиц по размеру (табл. 2). В каждой серии микросфер были выбраны дисперсные узкие фракции с близким средним диа- 
Таблица 1. Физико-химические характеристики узких фракций микросфер летучих зол от сжигания экибастузского (серия В) и ирша-бородинского углей (серия Кр)

Table 1. Physical and chemical characteristics of microsphere narrow fractions of fly ash from pulverized combustion of Ekibastuz (series B) and Irsha-Borodinsky coals (series Kr)

\begin{tabular}{|c|c|c|c|c|c|}
\hline Образец & $\mathrm{B} 12 / \mathrm{M} \Phi$ & $\mathrm{B} 13 / \mathrm{M} \Phi$ & $\mathrm{B} 14 / \mathrm{M} \Phi$ & Kp182 & Kp184 \\
\hline \multicolumn{6}{|c|}{ Физические характеристики } \\
\hline 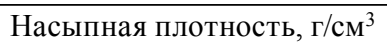 & 0.80 & 0.92 & 0.97 & 1.24 & 1.50 \\
\hline \multicolumn{6}{|c|}{ Химический состав } \\
\hline П.п.п. & 3.40 & 1.80 & 2.30 & 5.35 & 2.20 \\
\hline $\mathrm{SiO}_{2}$ & 63.73 & 60.66 & 60.80 & 24.73 & 34.08 \\
\hline $\mathrm{Al}_{2} \mathrm{O}_{3}$ & 26.26 & 26.72 & 26.61 & 8.42 & 8.05 \\
\hline $\mathrm{Fe}_{2} \mathrm{O}_{3}$ & 6.49 & 8.94 & 8.75 & 13.78 & 12.54 \\
\hline $\mathrm{CaO}$ & 1.17 & 1.45 & 1.53 & 38.32 & 33.97 \\
\hline $\mathrm{MgO}$ & 1.23 & 1.16 & 1.23 & 9.91 & 8.57 \\
\hline $\mathrm{SO}_{3}$ & 0.24 & 0.20 & 0.21 & 3.70 & 1.91 \\
\hline $\mathrm{Na}_{2} \mathrm{O}$ & 0.32 & 0.31 & 0.33 & 0.72 & 0.38 \\
\hline $\mathrm{K}_{2} \mathrm{O}$ & 0.45 & 0.46 & 0.43 & 0.21 & 0.33 \\
\hline $\mathrm{TiO}_{2}$ & 0.11 & 0.10 & 0.10 & 0.21 & 0.17 \\
\hline \multicolumn{6}{|c|}{ Фазовый состав, мас. \% } \\
\hline Стеклофаза & 67.2 & 67.4 & 66.7 & 50.3 & 50.5 \\
\hline Муллит & 17.9 & 18.2 & 20.4 & - & - \\
\hline Кварц & 13.9 & 12.3 & 10.3 & 4.9 & 7.1 \\
\hline Феррошпинель & 1.0 & 2.1 & 2.6 & 2.7 & 2.2 \\
\hline $\mathrm{Ca}_{2}(\mathrm{Al}, \mathrm{Fe}) \mathrm{O}_{5}$ & - & - & - & 13.8 & 13.9 \\
\hline $\mathrm{Ca}_{3} \mathrm{Al}_{2} \mathrm{O}_{6}$ & - & - & - & 7.9 & 10.7 \\
\hline $\mathrm{CaSO}_{4}$ & - & - & - & 3.3 & 1.1 \\
\hline $\mathrm{CaCO}_{3}$ & - & - & - & 0.4 & 0.2 \\
\hline $\mathrm{CaO}$ & - & - & - & 5.1 & 7.1 \\
\hline $\mathrm{Ca}(\mathrm{OH})_{2}$ & - & - & - & 6.0 & 2.4 \\
\hline $\mathrm{MgO}$ & - & - & - & 5.6 & 4.8 \\
\hline
\end{tabular}

* содержание оксидов кремния, алюминия, железа, кальция, магния, натрия, калия, титана и серы было пересчитано: из общего химического анализа вычтено значение п.п.п., сумма оксидов приведена к $100 \%$.

Таблица 2. Характеристики распределения частиц по размеру для исходных узких фракций микросфер после воздействия сжимающей нагрузки при 68.9 МПа и кислотного травления в $15 \% \mathrm{HCl}$ при $65{ }^{\circ} \mathrm{C}$ в течение 30 мин, мкм

Table 2. Particle size distribution characteristics for the initial microsphere narrow fractions, after crush resistant test at $68.9 \mathrm{MPa}$, and acid etching in $15 \% \mathrm{HCl}$ at $65^{\circ} \mathrm{C}$ for $30 \mathrm{~min}, \mu \mathrm{m}$

\begin{tabular}{|c|c|c|c|c|c|c|c|c|c|c|c|c|}
\hline \multirow[t]{2}{*}{ Образец } & \multicolumn{4}{|c|}{ Исходная узкая фракция } & \multicolumn{4}{|c|}{$\begin{array}{c}\text { После воздействия } \\
\text { сжимающей нагрузки }\end{array}$} & \multicolumn{4}{|c|}{$\begin{array}{c}\text { После кислотного } \\
\text { травления }\end{array}$} \\
\hline & $d_{\mathrm{cp}}$ & $d_{10}$ & $d_{50}$ & $d_{90}$ & $d_{\mathrm{cp}}$ & $d_{10}$ & $d_{50}$ & $d_{90}$ & $d_{\mathrm{cp}}$ & $d_{10}$ & $d_{50}$ & $d_{90}$ \\
\hline $\mathrm{B} 12 / \mathrm{M} \Phi$ & 4.5 & 1.0 & 3.5 & 9.2 & 4.0 & 1.0 & 3.2 & 8.3 & 4.3 & 1.0 & 3.4 & 8.8 \\
\hline В13/MФ & 7.8 & 1.0 & 6.4 & 16.8 & 7.2 & 1.2 & 5.9 & 15.1 & 9.0 & 1.4 & 7.4 & 18.8 \\
\hline $\mathrm{B} 14 / \mathrm{M} \Phi$ & 25.0 & 2.6 & 20.2 & 54.9 & 19.6 & 1.9 & 13.4 & 46.9 & 25.9 & 2.9 & 20.7 & 56.5 \\
\hline Кр182 & 4.4 & 0.3 & 3.8 & 8.8 & 4.2 & 0.2 & 3.8 & 9.1 & 7.5 & 1.2 & 6.7 & 14.5 \\
\hline Кр184 & 9.5 & 3.7 & 8.9 & 16.4 & 9.5 & 3.6 & 9.0 & 16.5 & 10.2 & 4.1 & 9.7 & 17.3 \\
\hline
\end{tabular}



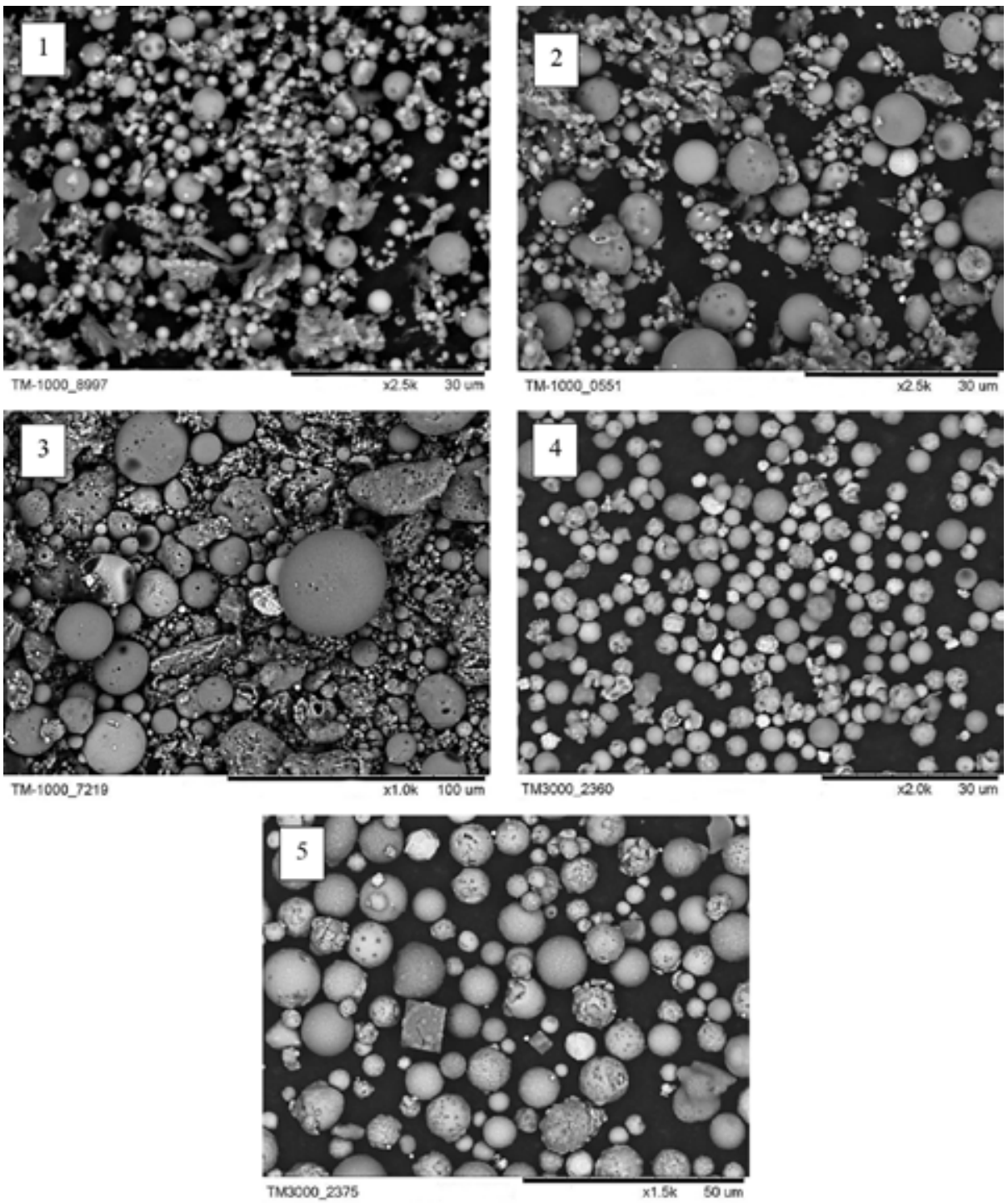

Рис. 1. Электронные микрофотографии узких фракций микросфер летучих зол: 1 - В12/МФ; 2 - В13/МФ; 3 - В14/МФ; 4 - Кр182; 5 - Кр184

Fig. 1. SEM images of microsphere narrow fractions from fly ash: 1 - B12/MF; 2 - B13/MF; 3 - B14/MF; 4 $\mathrm{Kr} 182 ; 5-\mathrm{Kr} 184$

метром глобул (4.5 и 4.4, 7.8 и 9.5 мкм); дополнительно в серии В была выбрана более крупная фракция со средним диаметром 25 мкм (табл. 2). На рис. 1 представлены электронные микрофотографии этих фракций, демонстрирующие сферичность частиц и размерную однородность сырья.

Основными компонентами химического состава узких фракций микросфер серии В являются $\mathrm{SiO}_{2}$ и $\mathrm{Al}_{2} \mathrm{O}_{3}$, суммарное содержание которых достигает 87-90 мас. \%; фазовый состав включает около 67 мас. \% стеклофазы, 10-14 мас. \% фазы кварца, 18-20 мас. \% муллита, 1-3 мас. \% феррошпинельной фазы (табл. 1). Основным компонентом химического состава фракций серии Кр является $\mathrm{CaO}-34-38$ мас. \%, доля $\mathrm{SiO}_{2}$ составляет 25-34, $\mathrm{Fe}_{2} \mathrm{O}_{3}-13-14$, 
$\mathrm{Al}_{2} \mathrm{O}_{3}$ - около 8 мас. \%; основные кристаллические фазы представлены кальцийсодержащими соединениями - 35-37 мас. \%, в том числе алюмоферрит кальция около 14 мас. \% и трехкальциевый алюминат - 8-11 мас. \%, доля кристаллического кварца составляет 5-7, аморфной стеклофазы - 50 мас. \% (табл. 1).

Прочностные характеристики узких фракций микросфер были определены по стандартной методике испытаний пропантов [9] под воздействием сжимающей нагрузки при давлении $25.85,51.7$ и 68.9 МПа. Контроль над появлением разрушенных частиц во фракциях осуществляли определением характеристик распределения по размеру (табл. 2) и по внешнему виду образцов на электронных микрофотографиях (рис. 2).
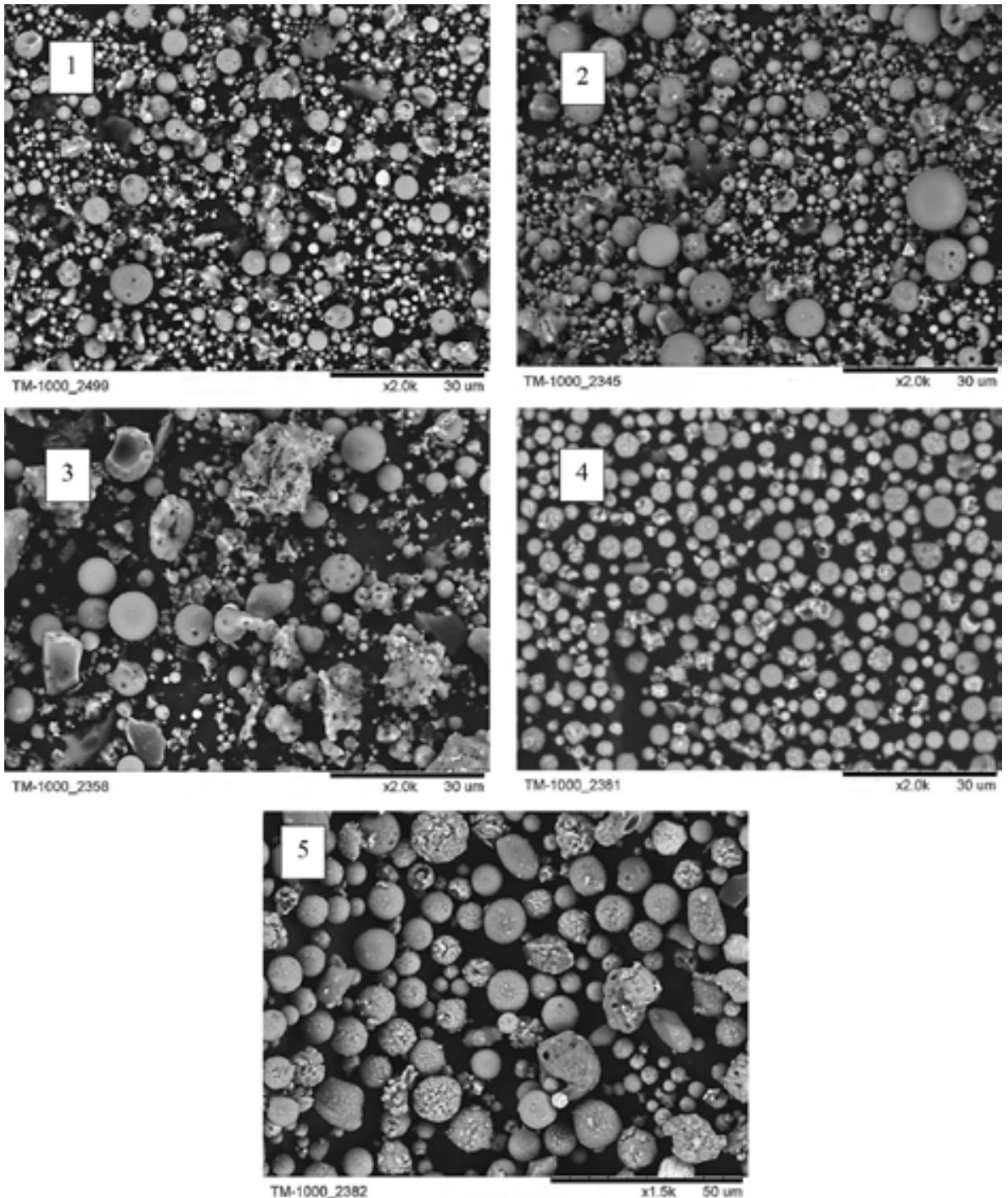

Рис. 2. Электронные микрофотографии узких фракций микросфер после воздействия сжимающей нагрузки при давлении 68.9 МПа: 1 - В12/МФ; 2 - В13/МФ; 3 - В14/МФ; 4 - Кр182; 5 - Кр184

Fig. 2. SEM images of microsphere narrow fractions after crush resistant test at 68.9 MPa: 1 - B12/MF; 2 - B13/ MF; 3 - B14/MF; 4 - Kr182; 5 - Kr184 
Установлено, что под воздействием сжимающей нагрузки 25.85 и 51.7 МПа разрушения микросфер не происходит во всех исследуемых фракциях (табл. 2). Средний диаметр частиц практически не изменяется, отклонение не превышает ошибку определения, составляя около 0.2 мкм. При увеличении давления сжимающей нагрузки до 68.9 МПа дисперсные зольные фракции с $d_{\mathrm{cp}} 4$ и 10 мкм обоих сырьевых источников практически полностью сохраняют свою целостность (рис. 2).

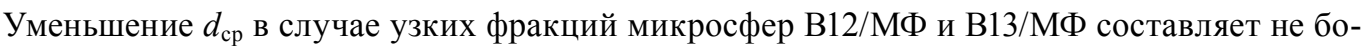
лее 0.6 мкм, для фракции Кр182 - 0.2 мкм, а для фракции Кр184 не наблюдаются изменения размерных характеристик (табл. 2). Для более крупной узкой фракции В14/MФ с $d_{\mathrm{cp}} 25$ мкм после воздействия максимальной сжимающей нагрузки 68.9 МПа установлено, что $d_{\text {ср }}$ уменьшился до 20 мкм (табл. 2), при этом на СЭМ-снимках обнаружены отдельные осколки разрушенных частиц (рис. 2.3).

Кислотостойкость узких фракций микросфер определяли согласно стандартной методике испытаний пропантов [9] путем определения растворимости образцов (по потере массы) в $15 \%$-й соляной кислоте при $65^{\circ} \mathrm{C}$ в течение 30 мин. Дополнительно, как и в случае определения прочностных характеристик узких фракций микросфер, осуществлялся контроль над изменением размерных характеристик образцов (табл. 2) и анализ СЭМ-снимков после кислотного травления (рис. 3).

Установлено, что наибольшей кислотостойкостью обладает дисперсная узкая фракция микросфер из летучей золы от сжигания экибастузского угля В12/МФ с $d_{\mathrm{cp}} 4$ мкм, для нее потеря массы составила минимальное значение 10 мас. \%. Для более крупных фракций этого сырьевого источника В13/МФ с $d_{\mathrm{cp}} 10$ мкм и В14/МФ с $d_{\mathrm{cp}} 25$ мкм потеря массы при кислотном травлении имеет несколько большее значение - 15 мас. \%. Дисперсные фракции из золы от сжигания ирша-бородинского угля Кр182 и Кр184 растворяются в соляной кислоте на 90 мас. \%, что связано с преобладанием в их составе кислоторастворимых соединений кальция и железа. Распределение частиц по размеру для травленых фракций незначительно сместилось в сторону крупных глобул для узких фракций микросфер обоих сырьевых источников (табл. 2).

Таким образом, зольные фракции микросфер, выделенные аэродинамическим методом из летучих зол от сжигания разных типов энергетических углей, имеют низкую насыпную плотность (табл. 1) и характеризуются узким распределение частиц по размеру (табл. 2). По своему химическому составу они относятся к разным системам: из золы экибастузского угля (серия В) $-\mathrm{SiO}_{2}-\mathrm{Al}_{2} \mathrm{O}_{3}-\mathrm{FeO}$, ирша-бородинского угля (серия $\mathrm{Kp}$ ) - $\mathrm{CaO}-\mathrm{SiO}_{2}-\mathrm{Al}_{2} \mathrm{O}_{3}-\mathrm{FeO}$. Фракции содержат разнообразные кристаллические фазы, в том числе в микросферах серии В фазу муллита, представляющую собой основу керамических материалов и ситаллов [24], в микросферах серии Кр - алюмоферрит кальция и трехкальциевый алюминат, являющиеся основными фазами портландцемента [25]. Для всех исследуемых фракций зольных микросфер обоих сырьевых источников характерна высокая прочность, кислотостойкостью обладают лишь фракции микросфер алюмосиликатного состава из летучей золы экибастузского угля (серия В).

Широкая вариация компонентного состава и возможность совместного использования исходных зольных фракций микросфер позволят разработать перспективные композиции и синтезировать материалы заданного состава с определенными свойствами. Узкие фракции микросфер серии В характеризуются низкими значениями насыпной плотности, высокой проч- 

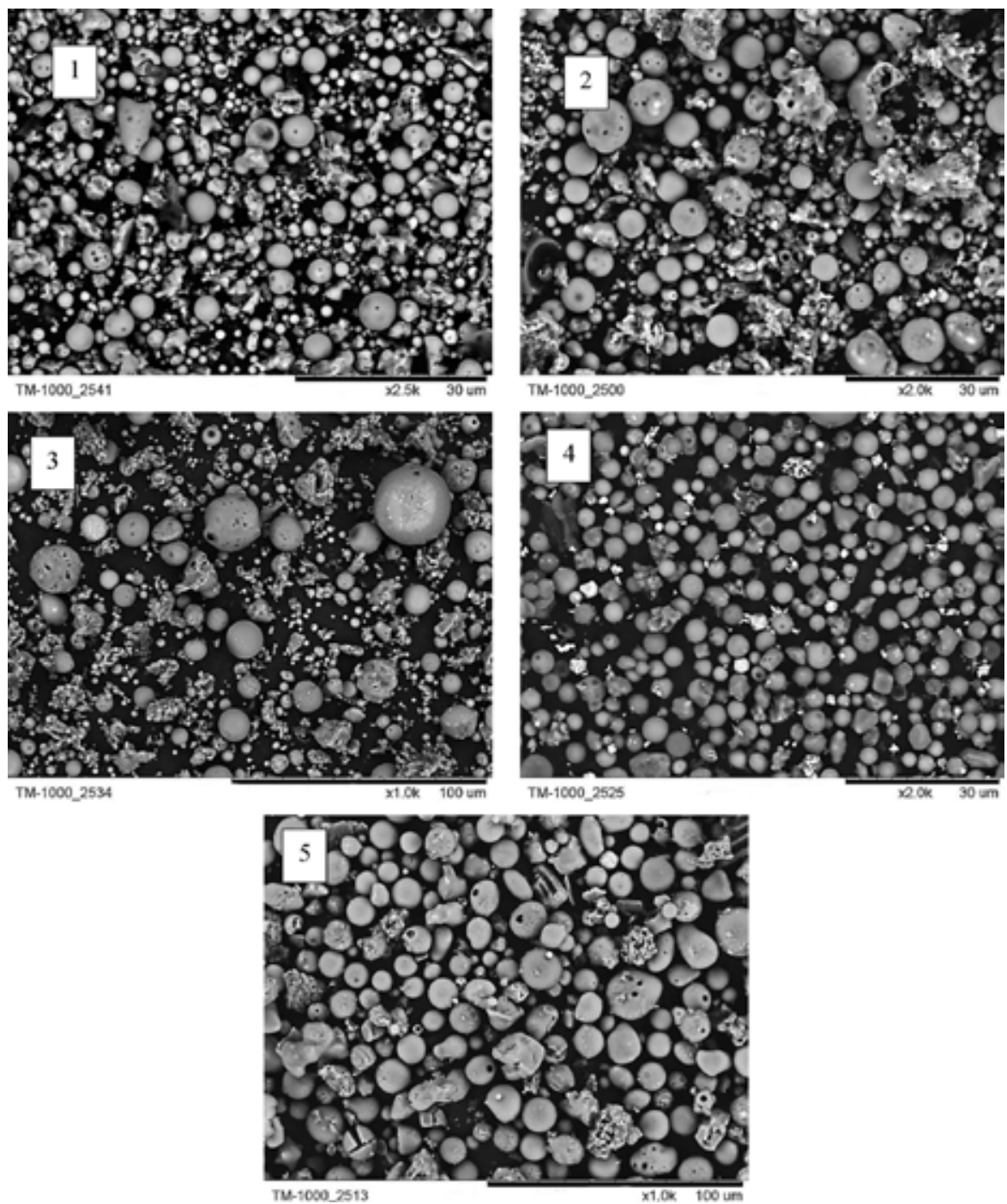

Рис. 3. Электронные микрофотографии узких фракций микросфер после кислотного травления: 1 - В12/ МФ; 2 - В13/МФ; 3 - В14/МФ; 4 - Кр182; 5 - Кр184

Fig. 3. SEM images of microsphere narrow fractions after acid etching: 1 - B12/MF; 2 - B13/MF; 3 - B14/MF; $4-\mathrm{Kr} 182 ; 5-\mathrm{Kr} 184$

ностью и кислотостойкостью, что обеспечивает перспективность их использования для получения облегченных высокопрочных композитных материалов, в том числе расклинивающих гранул пропантов [16]. Узкие фракции микросфер серии Кр содержат кристаллические фазы алюмоферрита кальция и трехкальциевого алюмината и могут быть успешно использованы для получения бесцементных высокопрочных композитных материалов [26].

\section{Выводы}

Исследование сопротивления раздавливанию для узких фракций микросфер из летучих зол от пылевидного сжигания экибастузского и ирша-бородинского углей показало, что дисперсные фракции с $d_{\mathrm{cp}} \leq 10$ мкм обоих сырьевых источников не подвергаются разрушению под 
воздействием сжимающей нагрузки до 68.9 МПа. Лучшей кислотостойкостью (потеря массы 10 мас. \%) обладает узкая фракция микросфер алюмосиликатного состава с $d_{\mathrm{cp}} 5$ мкм из золы

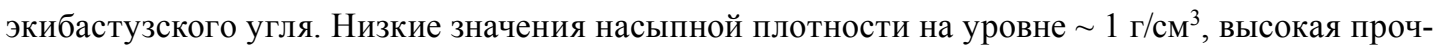
ность и кислотостойкость обеспечивают перспективность использования дисперсных узких фракций системы $\mathrm{SiO}_{2}-\mathrm{Al}_{2} \mathrm{O}_{3}-\mathrm{FeO}$ в качестве основы облегченных высокопрочных композитных материалов, в том числе расклинивающих гранул пропантов.

\section{Благодарности / Acknowledgements}

Авторы выражают благодарность сотрудникам ИХХТ СО РАН Л.А. Соловьеву за проведение количественного рентгенофазового анализа и А.В. Антонову за выполнение работ на сканирующем электронном микроскопе ТМ-1000.

We are grateful to staff members of the Institute of Chemistry and Chemical Technology of the Siberian Branch of the Russian Academy of Sciences (Krasnoyarsk) L.A. Solovyov for performing quantitative x-ray phase analysis and A.V. Antonov for performing work on scanning electron microscope TM-1000.

\section{Финансирование / Funding}

Исследование выполнено при финансовой поддержке Российского фонда фундаментальных исследований, Правительства Красноярского края РФ, Красноярского краевого фонда поддержки научной и научно-технической деятельности в рамках научного проекта № 18-43240002 «Разработка облегченных высокопрочных проппантов на основе узких фракций микросфер энергетических зол» и в рамках государственного задания Института химии и химической технологии СО РАН (проект АААА-А17-117021310222-4) с использованием сканирующего электронного микроскопа Красноярского регионального центра коллективного пользования ФИЦ КНЦ СО РАН.

The study was supported by Russian Foundation for Basic Research, Government of Krasnoyarsk Territory, and Krasnoyarsk Science Foundation (project no. 18-43-240002 Development of lightweight high-strength proppants based on microsphere narrow fractions of coal fly ash) and performed at the Institute of Chemistry and Chemical Technology, Siberian Branch, Russian Academy of Sciences within the framework of a state contract (AAAA-A17-117021310222-4) using the scanning electron microscope of the Krasnoyarsk regional center of collective use of FRC KSC SB RAS.

\section{Список литературы / References}

1. Yao Z.T., Ji X.S., Sarker P.K., Tang J.H., Ge L.Q., Xia M.S., Xi Y.Q. A comprehensive review on the applications of coal fly ash. Earth-Science Reviews 2015. Vol. 141, P. 105-121.

2. Vassilev S.V., Vassileva C.G. Methods for characterization of composition of fly ashes from coal-fired power stations: A critical overview. Energy and Fuels 2005. Vol. 19(3), P. 1084-1098.

3. Blissett R.S., Rowson N.A. A review of the multi-component utilisation of coal fly ash. Fuel 2012. Vol. 97, P. 1-23.

4. Belviso C. State-of-the-art applications of fly ash from coal and biomass: A focus on zeolite synthesis processes and issues. Prog. Energy Combust. Science. 2018. Vol. 65, P. 109-135. 
5. He Y., Cheng W., Cai H. Characterization of $\alpha$-cordierite glass-ceramics from fly ash. Journal of Hazardous Materials 2005. Vol. 120(1-3), P. 265-269.

6. Ji R., Zhang Z.T., Yan C., Zhu M.G., Li Z.M. Preparation of novel ceramic tiles with high $\mathrm{Al}_{2} \mathrm{O}_{3}$ content derived from coal fly ash. Constr. Build. Mater. 2016. Vol. 114, P. 888-895.

7. Wei Z., Hou J., Zhu Z. High-aluminum fly ash recycling for fabrication of cost-effective ceramic membrane supports. Journal of Alloys and Compounds 2016. Vol. 683, P. 474-480.

8. Liang F., Sayed M., Al-Muntasheri G.A., Chang F.F., Li L. A comprehensive review on proppant technologies. Petroleum 2016. Vol. 2, P. 26-39.

9. ГОСТ Р 51761-2013 Пропанты алюмосиликатные. Технические условия. М.: Стандартинформ, 2014. [GOST R 51761-2013 Aluminosilicate proppants. Specifcations. Moscow: Standardinform, 2014. (In Russ.)]

10. Патент 2129987 РФ. Симановский Б.А., Розанов О.М., Можжерин В.А., Мигаль В.П., Сакулин В.Я., Новиков А.Н., Салагина Г.Н., Штерн Е.А. Способ переработки алюмокремниевого сырья. Опубл. 10.05.1999. [Patent RU 2129987 Simanovsky B.A., Rozanov O.M., Mozherin V.A., Migal V.P., Sakulin V.Ya., Novikov A.N., Salagina G.N., Stern E.A. A method of processing aluminumsilicon raw materials. Publ. Date 10.05.1999. (In Russ.)]

11. Патент 2166079 РФ. Пястолов А.М., Миленин С.И. Пропант. Опубл. 27.04.2001 [Patent RU 2166079 Pyastolov A.M., Milenin S.I. Proppant. Publ. Date 27.04.2001. (In Russ.)]

12. Патент 2140875 РФ. Симановский Б.А., Розанов О.М., Можжерин В.А., Мигаль В.П., Сакулин В.Я., Новиков А.Н., Салагина Г.Н., Штерн Е.А. Алюмокремниевая шихта для производства гранул. Опубл. 11.10.1999 [Patent RU 2140875 Simanovsky B.A., Rozanov O.M., Mozherin V.A., Migal V.P., Sakulin V.Ya., Novikov A.N., Salagina G.N., Stern E.A. Silicon-aluminum mixture for the production of granules. Publ. Date 10.11.1999. (In Russ.)]

13. Parker M.A., Ramurthy K., Sanchez P.W. New proppant for hydraulic fracturing improves well performance and decreases environmental impact of hydraulic fracturing operations. Society of Petroleum Engineering 2012. SPE 161344.

14. Патент 2472837 РФ. Можжерин В.А., Мигаль В.П., Новиков А.Н., Салагина Г.Н., Сакулин В.Я., Штерн Е.А., Симановский Б.А., Розанов О.М. Легкий проппант. Опубл. 20.01.2013 [Patent RU 2472837. Mozherin V.A., Migal V.P., Novikov A.N., Salagina G.N., Sakulin V.Ya., Stern E.A., Simanovsky B.A., Rozanov O.M. Lightweight proppant. Publ. Date 20.01.2013. (In Russ.)]

15. Роговенко Е.С., Кушнерова О.А., Фоменко Е.В. Характеристика узких фракций микросфер летучих зол как основы облегченных высокопрочных материалов. Журнал Сибирского федерального университета. Химия 2019. Т. 12, № 2, С. 248-260. [Rogovenko E.S., Kushnerova O.A., Fomenko E.V. Characteristics of the narrow fractions of fly ash microspheres as the basis of lightweight high-strength materials. J. Sib. Fed. Univ. Chem. 2019. Vol. 12, No. 2, P. 248-260.]

16. Wu X., Huo Z., Ren Q., Li H., Lin F., Wei T. Preparation and characterization of ceramic proppants with low density and high strength using fly ash. Journal of Alloys and Compounds 2017. Vol. 702, P. 442-448.

17. Kushnerova O.A., Akimochkina G.V., Fomenko E.V., Rabchevskii E.V., Anshits A.G. One stage aerodynamic separation of fly ash from the pulverized combustion of Ekibastuz basin coal. Solid Fuel Chemistry 2018. Vol. 52(3), P. 188-200. 
18. Fomenko E.V., Anshits N.N., Kushnerova O.A., Akimochkina G.V., Kukhtetskiy S.V., Anshits A.G. Separation of Non-Magnetic Fine Narrow Fractions of PM10 from Coal Fly Ash, their Characteristics and Mineral Precursors. Energy and Fuels 2019. Vol. 33, No. 4, P. 3584-3593.

19. Fomenko E.V., Akimochkina G.V., Anshits A.G. Narrow dispersed fractions of high-calcium fly ash produced from the pulverized combustion of Irsha-Borodinsky coal. Thermal Engineering 2019. Vol. 66, No. 8, P. 560-568.

20. ASTM Standard C618-12a, Standard Specification for Coal Fly Ash and Raw or Calcined Natural Pozzolan for Use in Concrete. In 2012 Annual Book of ASTM Standards; American Society for Testing and Materials (ASTM): West Conshocken, PA 2012. URL: http://www.astm.org/Standards/ C618.htm, accessed June 24, 2015

21. ГОСТ 5382-91 Цемент и материалы цементного производства. Методы химического анализа. М.: Изд-во стандартов, 1991. [GOST 5382-91 Cements and materials for cement production. Chemical analysis methods. Moscow: Standards Publishing, 1991. (In Russ.)]

22. Rietveld H.M. A profle refnement method for nuclear and magnetic structures. Journal of Applied Crystallography 1969. Vol. 2, P. 65-71.

23. Fomenko E.V., Anshits N.N., Solovyov L.A., Mikhaylova O.A., Anshits A.G. Composition and morphology of fly ash cenospheres produced from the combustion of Kuznetsk coal. Energy and Fuels 2013. Vol. 27(9), P. 5440-5448.

24. Liang L. Mechanical properties analysis and microstructure of ceramic materials of mullite ceramic material. The International Journal of Electrical Engineering \& Education. 2018. Vol. 56( 4), P. 293-304.

25. Kurdowski W. Cement and Concrete Chemistry. Springer., 2014. 700 pp.

26. Sharonova O.M., Kirilets V.M., Yumashev V.V., Solovyov L.A., Anshits A.G. Phase composition of high strength binding material based on fine microspherical high-calcium fly ash. Construction and Building Materials 2019. Vol. 216, P. 525-530. 